\title{
Različni tipi besedotvornih morfemov pri današnjih slovenskih tvorjenkah
}

\author{
Irena Stramljič Breznik
}

Cobiss: 1.02

Prispevek obravnava po pogostnosti opazne zloženke s prevzetim sufiksoidom -mat. Na podlagi gradiva slovenskega referenčnega korpusa FidaPLUS so predstavljene njihove tvorbene in sestavinske značilnosti, ki kažejo na to, da so tvorjenke ali v celoti prevzete ali pa so rezultat hibridne tvorbe. S tvorbenega in pragmatičnega vidika se uvrščajo tako med potencialno kot tudi okazionalno leksiko.

Ključne besede: besedotvorje, zloženke, sufiksoid -mat

Various types of word-formational morphemes in current Slovenian neologisms

This article discusses observable compounds with the borrowed suffixoid -mat by frequency. Based on material from the FidaPLUS Slovenian reference corpus, their word-formational and componential characteristics are presented; these indicate that these are newly formed words, complete borrowings, or the result of hybrid word formation. From the perspective of word formation and pragmatics, they therefore rank among both potential and occasional vocabulary.

Key words: word formation, compounds, the suffixoid -mat

\section{Uvod}

1.0 Razpravljanje o tvorbeni produktivnosti sufiksoida - mat je povezano z vprašanjem prevzetih prvin in statusom sufiksoidov $\mathrm{v}$ besedotvornem sistemu slovenskega jezika.

Prevzemanje kot jezikovno stalnico je mogoče umestiti tudi v kontekst novih družbenih, političnih in kulturnih dogajanj, ki jih pokriva termin globalizacija, s katero se ukvarjajo ne samo ekonomisti, sociologi, politologi, antropologi in ekologi, ampak tudi lingvisti.

Poljski sociolog Hieronim Kubiak (Kryżan-Stanojević 2009: 10-11) razlikuje globalizacijo od integracije. Bistvo globalizacije je po njegovem prepričanju namreč gospodarsko združevanje raznovrstnih virov za materialno blagostanje, $\mathrm{v}$ integracijskih procesih pa je cilj združevanje skupne kulturne vrednosti in boljši način njihove izrabe. Vendar so integracijski procesi sodobne Evrope preblizu globa- 
- lizacijskim, saj je gospodarsko blagostanje zasenčilo željo po integraciji na temelju 팔 kulturnih in intelektualnih vrednosti.

Prav zato lingvisti, zavedajoč se neprestanih jezikovnih sprememb, opazujejo raznovrstne oblike jezikovne globalizacije (Kryżan-Stanojević 2009) in posledično ugotavljajo inovacije v slovanskih jezikih (Kryżan-Stanojević 2011).

\section{Internacionalizacija leksike $\mathrm{v}$ slovanskih jezikih}

2.0 Večina slovanskih lingvistov (Ohnheiser 2003; Waszakova 2005; Koriakowcewa 2009) ugotavlja, da gre za splošni proces internacionalizacije leksike v slovanskih jezikih. Težnje internacionalizacije se kažejo v prilagajanju in vključevanju internacionalizmov v osnovni nacionalni leksikalni sestav ter v oblikovanju novih besednih družin, $v$ aktivizaciji mednarodnih afiksov pri tvorjenju besed, v spreminjanju nekaterih zaimkov v prefiksoide, v razraščanju novih zloženk ter vznikanju novih besedotvornih vzorcev in struktur, ki se pojavljajo v različnih zvrsteh jezika.

2.1 Pomembna je opredelitev pojma internacionalizma kot interlingvalne jezikovne enote, ki jo je mogoče identificirati in raziskovati le s pomočjo primerjave več jezikov. Kot ugotavlja Kristina Waszakowa (2005: 25-35), je od dvajsetih let 20. stoletja, ko je na mednarodne elemente v evropskih jezikih opozoril Antoine Meillet, o internacionalizmih razpravljalo veliko lingvistov. Iz njihovih opredelitev sledi, da so to prvine mednarodne leksike, katerih večina izvira iz grških ali latinskih korenov, področno pa nastopajo $\mathrm{v}$ politiki, filozofiji, kulturi, znanosti, tehniki, ekonomiji, športu ... in jih je mogoče srečati v vsaj treh jezikih evropskega kulturnega kroga. Avtorica je spoznano razširila z dejstvom, da se internacionalizmi ne morejo omejevati zgolj na izraze grško-rimskega izvora, ampak jih je treba razširiti tudi na izraze iz drugih jezikov, npr. ruskega (perestrojka), češkega (robot), angleškega (bestseller), francoskega (bonton), nemškega (gastarbeiter), arabskega (džihad) idr. Internacionalizem - v slovenistični tradiciji imenovan tudi prevzeta beseda, ki se glede na stopnjo prilagoditve loči na tujko in izposojenko (Toporišič 2000: 131; Snoj 2006) - je v najširšem smislu lahko izraz (teater), morfem (anti-) ali besedna zveza (first lady). V slovanskih jezikih so bili internacionalizmi sprva posredovani prek nemščine in francoščine, $v$ novejšem času pa je zlasti za terminološko leksiko (znanost, tehnika, tehnologija) posrednik angleščina.

2.2 Kot je bilo že omenjeno, je pojave internacionalizacije $\mathrm{v}$ slovanskih in tudi drugih jezikih povzročil proces globalizacije. To pa pomeni, da besedotvorni inventar določenega jezika sestavljajo ne samo domače, ampak tudi prevzete prvine. Kristina Waszakova (2005: 56-57) ugotavlja, da se v večini besedotvornih raziskav slovanskih jezikov pojavlja tip različno poimenovanih afiksoidnih zloženk. Glede na položaj v prvem delu tvorjenke so imenovani morfemi prefiksoidi (npr. agro-, bio-, kiber-, disko-, eko- ...), če je pa taka sestavina v drugem delu (-bus, -fil, -man, -mat, $-\log ,-\log i j a,-f o b$...), pa sufiksoidi. Ista avtorica navaja podobno interpretaci- 
jo takih zloženk tudi v drugih jezikih, zlasti v angleškem, saj navaja termina suffix-like compouds in prefix-like compounds (Algeo 1991, po Waszakowa 2005: 57).

Dodati je treba, da afiksoid, pa najsi gre za prefiksoid ali sufiksoid, ni prvina, ki bi nastala zgolj s procesom prevzemanja, ampak tak status lahko dobijo tudi domače sestavine, ki so prvotno funkcionirale kot podstavne besede v zloženkah, a je pri pogostejši tovrstni tvorbi njihov pomen oslabel in so postale tvorbeno sredstvo. Status afiksoidov imajo tako v slovaščini (Furdik 2004: 46) zlasti -vod (vodovod, plinovod), -mer (plinomer, vodomer), -pis (dobropis), -slovje (jezikoslovje) oz. tudi malo- (malolastniški, malolitražen), vele- (velebanka), ki jih je manj. Podobno je bilo nakazano tudi že v slovenščini, npr. za -slovje (Toporišič 1981: 114).

\section{Prevzete sestavine $\mathrm{v}$ besedotvornem sistemu slovenščine}

3.0 Besedotvorni inventar slovenskega jezika ne predstavljajo samo domače, ampak tudi prevzete prvine. Pomembno vprašanje je seveda družljivost podstave in obrazila, kadar je ena od sestavin domača in druga prevzeta. Načeloma sicer velja, da se domača podstava druži z domačim obrazilom (brus-ač) oz. prevzeta podstava s prevzetim obrazilom (demonstr-ant). Možna pa je družljivost tudi prevzete in domače sestavine in takrat govorimo o mešani tvorjenki oz. hibridu s prevzeto podstavo in domačim obrazilom (celebral-ec, artilerij-ec) oz. domačo podstavo in prevzetim obrazilom (prevar-ant). Takih tvorjenk je danes vse več in niso omejene samo na izpeljanke, ampak so zlasti pogoste pri sestavljenkah, kjer se prevzeta predponska obrazila pridružujejo domačim podstavam (super-človek, ultra-lahek, mega-zmogljiv) ali pa prihaja do kombiniranih podstav v zloženkah (Stramljič Breznik 2005: 7-30), npr. evr-o-čakalnica, evr-o-besednjak, evr-o-bitka.

V slovenski besedotvorni teoriji so take zloženke obravnavane na dva načina. Jože Toporišič (2000: 188-189) jih del vključuje v tvorbeni sistem po enakih merilih kot domače medponsko-priponske podredne zloženke: sam-o-kres- $\emptyset$ : baro-graf- $\emptyset$, zakon-o-da-ja : ge-o-graf-ija oz. jih na podlagi dvonaglasnosti in brezpriponskosti drugega zloženskega dela (Toporišič 2000: 193-194) razvršča med samomedponske zloženke, npr. arteri-o-skleroza, astr-o-fizika, balne-o-terapija. Ada Vidovič Muha (1988: 161-163) pa tovrstne zloženke izloča iz tvorbeno-pretvorbenega sistema slovenskih tvorjenk, saj jim ni mogoče določiti skladenjske podstave. Obravnava jih kot zloženke z nadomestnimi (prevzetimi) sestavinami skladenjske podstave in jih razvršča med samo medponske podredne zloženke z nadomestno prvo, določujočo (agr-o-tehnika < tehnika za kmetijstvo), oz. drugo, določano sestavino (kostum-o-grafija < veda o kostumih) ali celo z obema nadomestnima sestavinama (aer-o-drom < cesta za letala).

3.1 Angleščina kot globalni jezik, tj. jezik interesno globalne informacije, ki ga določa tematska univerzalnost (Vidovič Muha 2003: 5-25), se s svojimi prvinami vpleta tudi v vsakdanje komunikacijske položaje. To je pokazala raziskava hibridnih tvorjenk, ki so velikokrat značilne za netradicionalno in k afektaciji težečo uporabo spletnega jezika mladih ter za ustvarjanje publicističnih priložnostnic, v 
- katerih prihaja do raznovrstnih možnosti prepletanja domačih in prevzetih jezikovnih prvin v nove kombinacije (Stramljič 2009: 165-178). Tovrstne hibridne zloženke kombinirajo prevzeto prvino $\mathrm{z}$ domačimi prvinami $\mathrm{v}$ besedotvorni vzorec po zakonitostih slovenskih besedotvornih vrst, tako da je zlahka mogoče najti ustrezni domači model, ki je bil pri tem uporabljen: zloženke: alkoljub (po npr. rodoljub), fotopis (npr. potopis), seksoslovje (npr. jezikoslovje), stripoigra (npr. veseloigra), kardiovadba (npr. telovadba). Zloženski hibridi drugega tipa pa predstavljajo kombinacijo domačih in prevzetih prvin, toda po analogiji tujega tvorbenega vzorca. V to skupino poleg zloženk (npr. kvazi-: kvazipametnjakovič, kvazisvoboda, kvazimaneken, kvazizdravjebrižnik, kvazimučeniški; mega-: megaslaven; multi-: multifant ipd.) spadajo take, kjer je prevzeta prvina v drugem delu (npr. -fest: bogračfest; -fil: Pohorjefil; -fob: romofob; -gate: rupargate; -holik, -holičarka, -holizem: čokoholik, fotoholik, šopingoholik, stripoholik; filmoholičarka, čokoholizem; -kracija: torbokracija; -land, -landija: Jonasland, Štajerland; črkolandija, Evrolandija, Qlandija; -logija: mehurčkologija, zobologija; -meter: kozmetometer, slinomater, županometer; -mobil: mamamobil; -pedija: telopedija; -skop: glasboskop, smrkoskop, Mariskop; -teka: smehoteka in -mat: slikomat, zdravkomat. In prav slednejmu tipu zloženk bomo v nadaljevanju posvetili posebno pozornost.

\section{Tvorjenke s sufiksoidom -mat}

4.0 Značilnosti zloženk s prevzetim sufiksoidom -mat bomo prikazali na podlagi gradiva slovenskega referenčnega korpusa FidaPLUS in s pomočjo večfunkcijskega orodja Sketch Engine (v nadaljevanju SkE). To ponuja klasične funkcije za iskanje konkordanc (iskanje po lemi, besednih oblikah, frazah, iskanje z jezikom CQL) ter standardne načine prikaza, razvrščanja in filtriranja ter shranjevanja konkordanc. Za raziskavo je bistvena korpusna funkcija, s katero je mogoče izdelati seznam besed, ki zbere in frekvenčno uredi vse besedne oblike oz. leme v korpusu. Iz tako pridobljenega seznama so bile izločene enote, pri katerih je šlo zgolj za tipkarsko napako ali pa so bila lastna imena, ki so kazala naključno izrazno homonimijo, nastalo s krnjenem in sklapljanjem sestavin, npr. Energomat 'montažno podjetje, ki se ukvarja z materialom za energetiko'.

4.1 Kvantitativni podatki, izhajajoči iz števila pojavitev različnic s sestavino -mat, so tile: avtomat (7138), bankomat (3324), tempomat (608), parkomat (427), kondomat (286), iglomat (201), infomat (193), ledomat (108), rolomat (41), kavomat (38), kartomat (37), zdravkomat (31), videomat (28), knjigomat (27), promilomat (24), hidromat (23), tankomat (20), avtobankomat (17), polavtomat (16), šankomat, aeromat, alkomat (13), promillomat (11), fotoavtomat (10), konvektomat (8), kruhomat, problemat, euromat (7), cambiomat, spletomat, testomat, multimat, bonomat, vodomat (5), superavtomat (4), nivomat, halomat, natakomat, picomat, kinoavtomat, turbomat, webomat (3), liftomat, Jodlavtomat, labelomat, Plastomat, čevljomat, štumfomat, fenomat, evromat, porkomat, klonomat (2), automat, cashomat, šalomat, čokomat, žarkomat, baromat, laudromat, parfumomat, puromat, sla- 
domat, mobikartomat, kavoavtomat, borzomat, babymat, filmomat, senzomat, otrokomat, autobankomat, aqvamat, pijačomat (1).

4.2 Besedotvornovrstno so tvorjenke z -mat samostalniške podredne zloženke. Tvorbena analogija izvira iz vzorca avtomat, kar je prevzeto prek nem. Automat in lat. automatus iz gr. automatos, ki je zloženka iz gr. autos 'sam' in trpnega deležnika glagola memona 'mislim, spominjam se', s prvotnim pomenom *'kdor sam misli' (Snoj 2003: 26). Korpusno gradivo prinaša tipološko dve skupini takih tvorjenk. Peščico primerov predstavljajo zgledi, ki imajo v drugem delu leksem -avtomat (polavtomat, fotoavtomat, jodlavtomat, kavoavtomat, kinoavtomat, superavtomat), -bankomat (avtobankomat), -kartomat (mobikartomat). Pri njih bodisi gre za skladenjsko podstavo, ustrezno medponskim podrednim zloženkam (npr. kav-o-avtomat $<$ avtomat za kavo) ali celo sestavljenkam (super-avtomat $<$ največji, najboljši avtomat). Drugo, večjo skupino pa tvorijo zloženke, v katerih nastopa v drugem delu zloženk sufiksoid -mat.

4.3 S stališča sestavinske strukture imajo tvorjenke $\mathrm{z}$-mat $\mathrm{v}$ prvem delu prevzeto ali pa domačo sestavino. Prevzete sestavine v prvem delu so lahko tudi citatne (auto-, cash-, cambio-, laundr-, web-, baby-, aqva-). Predvidevamo lahko, da so take tvorjenke v celoti prevzete iz tujega jezika. Sicer pa v prvem delu prevladujejo t. i. vezani mednarodni prefiksoidi (alko-, avto-, aero-, bio-, evro-, foto-, info-, hidro-, moto-, multi-, tempo-, tehno-, turbo-, video-).

Prav tako se v prvem delu tovrstnih zloženk lahko pojavlja zelo širok nabor ustaljenih leksemov slovenščine. Zanje je tipično, da se s sestavino -mat družijo z medponskim morfemom -o-, tako da se jim odvzame le končnica (bank- < banka, bon-, borz-, bar-, čevlj-, fen-, film-, led-, igl-, kav-, kart-, klon-, knjig-, konvent-, kruh-, label-, otrok-, parfum-, pic-, pijač-, problem-, promil-, sam-, splet-, šank-, šal-, štumf-, tank-, test-, vod-, pur-, žark-), ali pa je medpona homonimna z izglasjem leksema (hal- < halo, rol- < rolo, niv- < nivo, zdravk- $<$ zdravko). Nekateri leksemi v položaju pred medpono doživijo tudi večje krajšanje kot zgolj odvzem končnice (čok- < čokolada, kond- < kondom, park- < parkiranje, natak- < natakanje, plast- < plastika, konvekt- < konvekcija, slad- < sladoled, senz- < senzor, simpt- < simptom).

\section{Besedilna pojavnost tvorjenk s sufiksoidom -mat}

5.0 Iz kvantitativnih podatkov je mogoče razbrati pogostnost in v tem smislu tudi izpeljati interpretacijo o ustaljenosti tovrstnih zloženk. Visoko pojavnost imajo tvorjenke, ki se pojavljajo v publicistiki ali pa strokovno specializiranih revijah in imajo pomen 'naprava, ki je povezana s samodejnim izdajanjem/ustvarjanjem predmetov (kavomat, ledomat) ali elektronskih storitev (bankomat, infomat)'.

5.1 Tvorjenke z nižjo pojavnostjo so lahko izrazi, ki sicer izkoriščajo ustaljeni tvorbeni vzorec $X-+$-mat, vendar še zmeraj nastopajo kot potencialne besede. Na 
- to pogosto kaže raba iz korpusnih podatkov, npr. zdravkomat (Dnevnik): »Raču[स] nalnik, ljubiteljsko imenovan ,zdravkomat', bo v prihodnje Slovencem verjetno poN trjeval zdravstvene kartice«; porkomat (Kmetovalec): »Z napravo s komercialnim - nazivom porkomat (krmljenje na poziv) imenujemo računalniško suho krmljenje 저 plemenskih svinj v skupinskih čakališčih.«

5.2 Povsem drugačne so priložnostnice s pojavnostjo 2 ali 1, ki so nastale zgolj kot rezultat vzporednega, ekspresivnega, za enkratno rabo ustvarjenega poimenovanja, kot zgovorno kažeta naslednja dva zgleda: otrokomat (Nedeljski dnevnik): »[...] da preneha obstajati le ,kot otrokomat", uvoženi strojček za slovensko otročad «; klonomat (Delo): »Beseda knjigomat, kakor so po(ne)srečeno prevedli avtomatsko izposojo knjig (prvo tovrstno napravo na naših tleh so včeraj slovesno predstavili v Centralni tehnični knjižnici v Ljubljani), nenaključno močno spominja na bankomat. Zaporedju obeh avtomatov bo verjetno sledil še kak ,mat‘. Po prebiranju novic o kloniranih prašičih ponujamo tvorcem besednih novotarij brezplačno v premislek ime klonomat. Morda bo uporaben tudi za kloniranje knjigarjev in njihovih skovank.«

\section{Sklep}

Raziskava medponskoobrazilnih samostalniških zloženk s sufiksoidom -mat na razpoložljivem gradivu korpusa FidaPLUS je tudi v slovenščini pokazala visoko produktivnost prevzetega tvorbenega vzorca. Dotok tovrstnih tvorjenk je omogočen tako z neposrednim prevzemanjem (babymat, cashomat) kot z zapolnjevanjem tvorbenega vzorca z domačimi leksemi v prvem delu (knjigomat, iglomat).

Pogostnost tovrstnih tvorjenk in njihova pojavnost $\mathrm{v}$ besedilnih virih s stališča okoliščin rabe nedvoumno kažeta na tri skupine tvorjenk. Prvo tvorijo internacionalizmi, ustaljeni tudi v drugih (ne)slovanskih jezikih (npr. bankomat, tempomat, infomat), drugo nizkofrekventne tvorjenke, ki si kot potencialne besede šele utirajo pot v strokovni ali širši rabi (npr. picomat, porkomat), tretjo pa priložnostne tvorjenke z ekspresivnim nabojem, ustvarjene zgolj za enkratno priložnost (npr. štumfomat, žarkomat).

Splošna težnja internacionalizacije v leksiki sodobnih nacionalnih jezikov se tako odraža z vedno večjo presečno množico skupnih leksemov, hkrati pa z vse večjo družljivost prevezetega in domačega, kar vodi v hibridizacijo tvorjene leksike.

\section{Literatura}

Furdík 2004 = Juraj Furdík, Slovenská slovotvorba: teória, opis, cvičenia, ur. Martin Ološtiak, Prešov: Náuka, 2004.

Koriakowcewa 2009 = Elena Koriakowcewa (ur.), Przejawy internacjonalizacji $w$ językach słowiańskich, Siedlce: Wydawnictwo Akademii Podlaskej, 2009. 
Kryżan-Stanojević 2009 = Barbara Kryżan-Stanojević (ur.), Lice i naličje jezične globalizacije, Zagreb: Srednja Europa, 2009.

Kryżan-Stanojević 2011 = Barbara Kryżan-Stanojević (ur.), Inovacije u slavenskim jezicima, Zagreb: Srednja Europa, 2011 (Biblioteka Srednje Europe).

Ohnheiser 2003 = Ingeborg Ohnheiser (ur.), Komparacja współczesnych języków słowiańskich 1: słowotwórstwo/nominacja, Opole: Uniwersytet Opolski Instytut Filologii Polskiej - Opolskie Towarzystwo Przyjaciół Nauk, 2003.

Snoj 2003 = Marko Snoj, Slovenski etimološki slovar, Ljubljana: Modrijan, ${ }^{2} 2003$.

Snoj 2006 = Marko Snoj, O tujkah in izposojenkah v slovenskem jeziku, Slovensko jezikoslovje danes = Slavistična revija 54 (2006), posebna št., 343-350.

Stramljič Breznik 2009 = Irena Stramljič Breznik, Hibridizacija novejših slovenskih tvorjenk, v: Przejawy internacjonalizacji w językach słowiańskich, ur. Elena Koriakowcewa, Siedlce: Wydawnictwo Akademii Podlaskiej, 2009, $165-178$.

Toporišič 1981 = Jože Toporišič, Slovenski knjižni jezik 2, Maribor: Obzorja, 1981. Toporišič 2000 = Jože Toporišič, Slovenska slovnica, Maribor: Obzorja, ${ }^{4} 2000$.

Vidovič-Muha 1988 = Ada Vidovič-Muha, Slovensko skladenjsko besedotvorje ob primerih zloženk, Ljubljana: Znanstveni inštitut Filozofske fakultete - Partizanska knjiga, 1988.

Waszakova 2005 = Krystyna Waszakowa, Przejawy internacjonalizacji $w$ słowotwórstwie współczesnej polszczyzny, Warszawa: Wydawnictwa Uniwersytetu Warszawskiego, 2005.

\section{Various types of word-formational morphemes in current Slovenian neologisms}

\section{Summary}

This article discusses infix-suffix nominal compounds using the suffixoid -mat, which are considered internationalisms due to their general distribution in languages. Available material from the FidaPLUS corpus also shows the high productivity of this borrowed word-formational pattern in Slovenian. Based on its occurrence in text sources, from the point of view of usage circumstances it clearly points to three groups of newly formed words. The first is comprised of internationalisms that are also established in other Slavic and non-Slavic languages (e.g., bankomat 'cash dispenser', tempomat 'cruise control', infomat 'information terminal'), the second is comprised of infrequent coinages that are still making their way into technical or general use as potential lexemes (e.g., picomat 'pizza vending machine', porkomat 'automatic pig feeder'), and the third group is comprised of nonce creations with an expressive character, simply formed for unique occasions (e.g., štumfomat 'sock dispenser', žarkomat 'light saber'). 